\title{
Antibiotic Sensitivity Pattern of Uropathogens in Diabetic Women with Asymptomatic Bacteriuria
}

\author{
Nadeem Islam Sheikh ${ }^{1}$, Ambreen Zahoor ${ }^{2}$, Mehreen Baber ${ }^{3}$, Zaidan Idrees Choudhary ${ }^{4}$ \\ Professor, Department of Medicine, HBS Medical \& Dental College, Islamabad, Pakistan \\ Assistant Professor, Department of Medicine, HBS Medical \& Dental College, Islamabad, Pakistan \\ Assistant Professor, Department of ENT, HBS Medical \& Dental College, Islamabad, Pakistan \\ Assistant Professor, Department of Psychiatry, HBS Medical \& Dental College, Islamabad, Pakistan
}

\begin{abstract}
Background: More than 150 million people around the globe are diagnosed with urinary tract infections every year. Failure to treat these infections with proper antibiotics can lead to serious complications. The objective of this study was to investigate antibiotic sensitivity and resistance pattern of urinary isolates in type-2 diabetic women with asymptomatic bacteriuria.

Material and Methods: This cross-sectional descriptive study was conducted at the HBS General Hospital, Islamabad, from March 2017 to August 2019. A total of 270 females with the diagnosis of type-2 diabetes mellitus were included in the study. Uropathogens were isolated from urine samples and antibiotic sensitivity testing was conducted. Demographic and clinical information was recorded on a pre-designed proforma. The data was analyzed using SPSS version 20.

Results: The mean age of the study sample was 50 years (SD \pm 5.5 ) while the mean $\mathrm{HbA} 1 \mathrm{c}$ levels were $8.98 \mathrm{~g} / \mathrm{dL}$ (SD \pm $0.8 \mathrm{~g} / \mathrm{dl}$ ). Uropathogens were found in the urine cultures of 106 (39.3\%) patients. Extended Spectrum Beta-Lactamase producing (ESBL) Escherichia coli (E. coli) was the most common organism ( $n=46,43.4 \%)$ which was sensitive to tazobactam, tazocin and co-trimoxazole. Nitrofurantoin was the most effective antibiotic with $62.5 \%$ isolates sensitive to it. All of the pathogens were resistant to ciprofloxacin.

Conclusions: Asymptomatic bacteriuria is common in type-2 diabetic women with ESBL E. Coli being the most common organism isolated from urine cultures. There is a significant resistance to antibiotics among the uropathogens isolated from these patients.

Key words: Asymptomatic bacteriuria, Diabetes mellitus, E. coli, Urinary tract infection

\begin{tabular}{|c|c|c|}
\hline Authors' Contribution: & Correspondence: & Article info: \\
\hline $\begin{array}{l}{ }^{1-3} \text { Conception; Literature research; } \\
\text { manuscript design and drafting; Critical } \\
\text { analysis and manuscript review; Data } \\
\text { analysis; }{ }^{4} \text { Manuscript Editing. }\end{array}$ & $\begin{array}{l}\text { Nadeem sheikh } \\
\text { Email: nadeem.islam@hotmail.com }\end{array}$ & $\begin{array}{l}\text { Received: December 4, } 2019 \\
\text { Accepted: June 19, } 2020\end{array}$ \\
\hline $\begin{array}{l}\text { Cite this article. Sheikh NI, Zahoor A, Baber } \\
\text { Uropathogens in Diabetic Women with As) }\end{array}$ & $\begin{array}{l}\text { houdhary ZI. Antibiotic Sensitivity Pattern of } \\
\text { omatic Bacteriuria. J Islamabad Med Dental }\end{array}$ & $\begin{array}{l}\text { Funding Source: Nil } \\
\text { Conflict of Interest: Nil }\end{array}$ \\
\hline
\end{tabular}

Coll.2020; 9(2): 140-144. Doi: 10.35787/jimdc.v9i2.469
\end{abstract}

\section{Introduction}

The incidence of diabetes mellitus is increasing throughout the world and it poses a serious public health threat in developing countries. Chronic hyperglycemic state in diabetics is associated with long term organ damage and dysfunction. Diabetics are more prone to urinary tract infections ${ }^{1}$ and the risk of complications is increased in those with poor glycemic control. ${ }^{2}$ The underlying mechanism involves presence of static pool of urine due to dysfunctional bladder which serves as a favorable 
medium for bacterial growth. ${ }^{3}$ On the other hand, hyperglycemic urine promotes rapid pathogen proliferation. ${ }^{4}$ Even though the precise mechanism for the predilection of pathogens to cause UTI in diabetics is unclear, the defect in IL-8 and IL-6 release increases the adherence of microorganisms to uroepithelial cells. Experimentally it has been seen that osmotic diuresis secondary to glycosuria predisposes to ascending E. coli infections. 5, 6

In the last three decades inappropriate use of antibiotics has increased microbial resistance and pattern of infection. ${ }^{7}$ Change in organisms responsible for UTI and resistance to commonly prescribed medicines is also reported. The worldwide escalation in both community and hospital acquired antimicrobial resistance is threatening the ability to treat patients with UTI. ${ }^{8,9}$ Successful management of UTI in diabetics is dependent upon the isolation of microorganism and use of effective antibiotic, as indiscriminate use often results in organ damage secondary to poor control of infection.

This study was undertaken to identify the microbial organisms responsible for silent urinary tract infections in type-2 diabetic women and to find out their drug susceptibility to commonly used antibiotics. This is important as injudicious use of antibiotics is common in our settings. With the identification of latest susceptibility and resistance patterns, local clinicians may be provided with evidence-based guidelines for the treatment of UTI in their patients.

\section{Material and Methods}

This descriptive cross-sectional study was conducted at the HBS General Hospital, Islamabad, from March, 2017 to August, 2019. Ethical approval was taken from the Institutional Ethics Review Committee. Non-probability convenience sampling technique was used and all type-2 diabetic women presenting to the medical OPD were included in the study. Patients with urogenital abnormalities and renal failure, those on antibiotics or immune suppressive medications and pregnant females were excluded. The design and objectives of the study were explained to the patients before taking informed consent.

A total of 270 females with a diagnosis of type-2 diabetes mellitus were included in the study. Laboratory investigations for patients comprised of complete blood picture, fasting blood glucose level, glycosylated hemoglobin level, urine culture and routine examination (RE). Urinary samples were collected by standard mid-stream clean catch method in a sterilized wide-mouth container that was covered with a tight-fit lid. Microscopic examination of a wet film of non-centrifuged urine was carried out to detect presence of pus cells, red blood cells and microorganisms. The urine samples were then processed for sensitivity and resistance by following the clinical laboratories standards institute (CLSI) guidelines. ${ }^{10}$ The antibiotics tested were imepenum, tazobactam, amikacin, gentamicin, fosomycin, nitrofurantion, cefixime, cefotaxime, norfloxacin, ciprofloxacin, amplicillin, amoxicillin-clavaulanic acid, tetracycline, cotrimoxazole, erythrocin, itraconazole and fluconazole. Asymptomatic bacteriuria was defined as presence of $10^{5} \mathrm{cfu} / \mathrm{ml}$ bacteria in urine without any symptoms of UTI. ${ }^{11}$

The demographic and clinical data was recorded on a pre-designed proforma and uploaded to SPSS version 20 for analysis. Results were reported as mean \pm standard deviation (SD) for continuous variables and as frequencies for categorical variables.

\section{Results}

A total of 270 women with type- 2 diabetes mellitus were included in the study. The mean age of the study sample was 50 years (SD \pm 5.5 ) with an age 
range of $35-65$ years. The mean duration of diabetes in the patients was 7 years $(S D \pm 1.2)$ while the mean $\mathrm{HbA} 1 \mathrm{c}$ levels were $8.98 \mathrm{~g} / \mathrm{dL}$ (SD \pm 0.8 $\mathrm{g} / \mathrm{dl})$. Out of the study samples, 106 urine cultures (39.3\%) were found to be positive for bacterial growth. The association of the demographic and clinical variables with positive urine culture is given in Table I.

\begin{tabular}{|c|c|c|c|}
\hline \multicolumn{4}{|c|}{$\begin{array}{l}\text { Table I: Association of clinicopathological } \\
\text { characteristics with positive urine culture }\end{array}$} \\
\hline & $\begin{array}{l}\text { No. of } \\
\text { Patients } \\
\mathrm{n}(\%)\end{array}$ & $\begin{array}{c}\text { Positive } \\
\text { Urine Culture } \\
\mathbf{n}(\%)\end{array}$ & $\begin{array}{c}\text { P. } \\
\text { value* }\end{array}$ \\
\hline Total & $270(100)$ & $106(39.3)$ & \\
\hline \multicolumn{3}{|c|}{ Age (year) } & \multirow{3}{*}{0.15} \\
\hline$<50$ & $162(60)$ & $58(35.8)$ & \\
\hline$>50$ & $108(40)$ & $48(44.4)$ & \\
\hline \multicolumn{3}{|c|}{ Illness duration (year) } & \multirow{3}{*}{0.84} \\
\hline$<7$ & $161(59.6)$ & $64(39.7)$ & \\
\hline$>7$ & $109(40.4)$ & $42(38.5)$ & \\
\hline \multicolumn{3}{|c|}{ HbA1c level (g/dl) } & \multirow{3}{*}{0.43} \\
\hline$<8.9$ & $148(54.8)$ & 55 (37.1) & \\
\hline$>8.9$ & $122(45.2)$ & $51(41.8)$ & \\
\hline
\end{tabular}

$* P$-value $<0.05$ was considered statistically significant

The most common organisms isolated from the cultures were ESBL E. coli (43.4\%) followed by E. coli (33\%), respectively. The details of the bacterial pathogens isolated from urine samples are given in Table II.

\begin{tabular}{|l|c|}
\hline \multicolumn{2}{|c|}{$\begin{array}{c}\text { Table II: Pathogens isolated from the urine samples } \\
\text { of the study patients }\end{array}$} \\
\hline $\begin{array}{l}\text { Bacteria in urine } \\
\text { culture }\end{array}$ & $\mathbf{n}(\%)$ \\
\hline E. coli (ESBL) & $46(43.4)$ \\
\hline E. coli & $35(33)$ \\
\hline Enterococcus (SPP) & $7(6.6)$ \\
\hline Klebsiella (ESBL) & $5(4.7)$ \\
\hline Enterococcus & $5(4.7)$ \\
\hline Klebsiella (SPP) & $4(3.7)$ \\
\hline Pseudomonas & $3(2.8)$ \\
\hline Proteus & $1(0.9)$ \\
\hline
\end{tabular}

ESBL- Extended-spectrum $\beta$-Lactamase-producing; SPP-Several species

The sensitivity and resistance patterns revealed that most common urinary isolate (ESBL E. coli) was sensitive to fosomycin, tazocin, cefotaxime, cotrimoxazole and levofloxacin. The details of the sensitivity and resistance patterns of the organisms are given in Table III.

\section{Discussion}

Urinary tract infections occur more frequently in diabetics than the general population and predispose to renal failure if not treated adequately with appropriate antibiotics. The resistance to antibiotics is continuously increasing but there is great variation in data regarding resistance rates from different countries. This study looked at the antibiotic sensitivity pattern of uropathogens isolated from female diabetic patients presenting to the medical OPD of a tertiary care hospital in Islamabad.

The current study showed that a significant number of the female patients had a positive urine culture $(n=106,39.3 \%)$. These results agree with the findings reported by Tahir and Qazi that showed prevalence of positive cultures to be $43 \%$ in diabetic population in Pakistan. ${ }^{12}$ This study included patients with symptoms of UTI, whereas the patients in our study were asymptomatic. The high number of diabetic females with a positive urine culture, without symptoms of UTI, raises the question of routine screening of these patients for bacteriuria to ensure early intervention and decrease in long term complications. The association between clinical variables and positive urine cultures was also assessed in our study.

The current study found ESBL E. coli ( $n=46,43.4 \%$ ) as the most common organisms in diabetic females with asymptomatic bacteriuria followed by $\mathrm{E}$. coli $(n=35,33 \%)$. The other organisms isolated from the study patients included Enterococcus SPP $(n=7$, $6.6 \%)$, Klebsiella $(n=5,4.7 \%)$, Enterococcus $(n=5$, $4.7 \%)$ and Pseudomonas $(n=3,2.8 \%)$ while Proteus 
Table III: Antibiotic Sensitivity and resistance pattern of isolated bacterial uropathogens

\begin{tabular}{|c|c|c|c|c|c|c|c|c|}
\hline Antibiotic & EC & $\begin{array}{c}E C \\
(E S B L)\end{array}$ & $\begin{array}{c}\text { Klebsiella } \\
\text { (ESBL) }\end{array}$ & $\begin{array}{c}\text { Klebsiella } \\
\text { (SPP) }\end{array}$ & Enterococcus & $\begin{array}{c}\text { Enterococcus } \\
\text { (SPP) }\end{array}$ & Proteus & Pseudomonas \\
\hline FM & $S$ & $\mathrm{~S}$ & $\mathrm{R}$ & $\mathrm{R}$ & $S$ & $\mathrm{R}$ & $\mathrm{R}$ & $R$ \\
\hline GM & $S$ & $\mathrm{R}$ & $\mathrm{R}$ & $\mathrm{R}$ & $\mathrm{R}$ & $\mathrm{R}$ & $\mathrm{R}$ & $R$ \\
\hline MEM & $S$ & $\mathrm{R}$ & $\mathrm{R}$ & $S$ & $\mathrm{R}$ & $\mathrm{R}$ & $S$ & $\mathrm{R}$ \\
\hline CTX & $S$ & $S$ & $\mathrm{R}$ & $\mathrm{R}$ & $\mathrm{R}$ & $\mathrm{R}$ & $\mathrm{R}$ & $\mathrm{R}$ \\
\hline TGN & $S$ & $\mathrm{R}$ & $\mathrm{R}$ & $\mathrm{R}$ & $S$ & $\mathrm{R}$ & $\mathrm{R}$ & $\mathrm{R}$ \\
\hline LEV & $S$ & $S$ & $\mathrm{R}$ & $S$ & $\mathrm{R}$ & $\mathrm{R}$ & $S$ & $\mathrm{R}$ \\
\hline COT & $S$ & $S$ & $\mathrm{R}$ & $\mathrm{R}$ & $\mathrm{R}$ & $\mathrm{R}$ & $S$ & $\mathrm{R}$ \\
\hline $\mathrm{MCN}$ & $S$ & $\mathrm{R}$ & $\mathrm{R}$ & $\mathrm{R}$ & $\mathrm{R}$ & $S$ & $\mathrm{R}$ & $\mathrm{R}$ \\
\hline AVE & $S$ & $S$ & $\mathrm{R}$ & $\mathrm{R}$ & $\mathrm{R}$ & $\mathrm{R}$ & $S$ & $\mathrm{R}$ \\
\hline TN & $S$ & $S$ & $S$ & $S$ & $\mathrm{R}$ & $\mathrm{R}$ & $\mathrm{R}$ & $\mathrm{R}$ \\
\hline NFN & $S$ & $\mathrm{~S}$ & $S$ & $\mathrm{R}$ & $S$ & $\mathrm{~S}$ & $\mathrm{R}$ & $\mathrm{R}$ \\
\hline VA & $\mathrm{R}$ & $\mathrm{S}$ & $\mathrm{R}$ & $\mathrm{R}$ & $\mathrm{R}$ & $\mathrm{R}$ & $\mathrm{R}$ & $S$ \\
\hline AK & $\mathrm{R}$ & $\mathrm{S}$ & $\mathrm{R}$ & $\mathrm{R}$ & $\mathrm{R}$ & $\mathrm{R}$ & $\mathrm{R}$ & $\mathrm{R}$ \\
\hline CIP & $\mathrm{R}$ & $\mathrm{R}$ & $\mathrm{R}$ & $\mathrm{R}$ & $R$ & $\mathrm{R}$ & $\mathrm{R}$ & $\mathrm{R}$ \\
\hline SPR & $R$ & $\mathrm{R}$ & $\mathrm{R}$ & $S$ & $S$ & $\mathrm{R}$ & $\mathrm{R}$ & $R$ \\
\hline CFM & $\mathrm{R}$ & $\mathrm{R}$ & $\mathrm{R}$ & $\mathrm{R}$ & $\mathrm{R}$ & $\mathrm{R}$ & $\mathrm{R}$ & $S$ \\
\hline CTZ & $\mathrm{R}$ & $\mathrm{R}$ & $R$ & $\mathrm{R}$ & $R$ & $S$ & $\mathrm{R}$ & $\mathrm{R}$ \\
\hline AP & $\mathrm{R}$ & $S$ & $R$ & $\mathrm{R}$ & $\mathrm{R}$ & $\mathrm{R}$ & $\mathrm{R}$ & $S$ \\
\hline CPS & $\mathrm{R}$ & $S$ & $S$ & $\mathrm{R}$ & $\mathrm{R}$ & $\mathrm{R}$ & $\mathrm{R}$ & $\mathrm{R}$ \\
\hline CXT & $\mathrm{R}$ & $\mathrm{R}$ & $\mathrm{R}$ & $\mathrm{R}$ & $\mathrm{R}$ & $S$ & $\mathrm{R}$ & $S$ \\
\hline OLF & $\mathrm{R}$ & $\mathrm{R}$ & $\mathrm{R}$ & $\mathrm{R}$ & $S$ & $\mathrm{~S}$ & $\mathrm{R}$ & $S$ \\
\hline IMI & $\mathrm{R}$ & $\mathrm{R}$ & $\mathrm{R}$ & $\mathrm{R}$ & $S$ & $S$ & $\mathrm{R}$ & $S$ \\
\hline PXN & $\mathrm{R}$ & $\mathrm{R}$ & $\mathrm{R}$ & $\mathrm{R}$ & $S$ & $S$ & $\mathrm{R}$ & $S$ \\
\hline
\end{tabular}

R-drug resistance; S-drug sensitive; EC-E. coli; ESBL-extended-spectrum beta-lactamase; SPP-several species; FM-fosomycin; GMgentamycin; MEM-meropenum; CTX-cefotaxime; TGN-tigecycline; LEV-levofloxacin; COT-cotrimoxazole; MCN-minocycline; AVEamoxiclav; TN-Tazocin; NFN-nitrofurantion; VA-vancomycin; AK-amikacin; CIP-Ciprofloxicin; SPR-sparfloxicin; CFM-cefixime; CTZceftazadime; AP-ampicillin; CPS-cefoperazoneculbactam; CXT-cefoxitine; OLF-ofloxacine; IMI-imipenum; PXN-polymyxin

was isolated from one $(0.9 \%)$ sample only. In a number of similar studies, the most common organism isolated from the urine samples has been E. coli. However, the other organisms show a broad variety. A study published by Bharti et al. showed $\mathrm{E}$. coli as the most common organism $(47.6 \%)$, followed by Candida (33.3\%), Pseudomonas (9.5\%), Klebsiella (4.76\%) and Citrobacter (4.76\%). ${ }^{13}$ In a study by Simkhada on 100 diabetic patients, E. coli was the most common organism (52.38\%), followed by Klebsiella (14.28\%), Pseudomonas, and Proteus (9.52\% each), respectively. ${ }^{14}$

In this study, we also assessed the antibiotic sensitivity of various pathogens to a number of antibiotics and the results paint a worrying picture. No single antibiotic was effective against all organisms isolated from the samples. Nitrofurantoin was the most effective antibiotic with $62.5 \%$ isolates sensitive to it, followed by tazocin and levofloxacin, which were effective against $50 \%$ of the isolates. All of the pathogens were resistant to ciprofloxacin which is one of the most commonly used treatments for UTI in our settings. Significant resistance was also observed against amikacin, cefixime and ceftazadime as they were effective against only $12.5 \%$ of the pathogens. The common uropathogen isolated from our study patients, ESBL E. Coli was found to be most sensitive to tazobactam, tazocin and cotrimoxazole. The latter presents an interesting scenario of an old drug, which has been out of use for a number of years that may again become useful as the organisms become resistant to newer 
medications. A similar study was conducted by Boyko et al. who concluded that among the antibiotics, aminoglycosides (34\%) and nitrofurantoin (21\%) showed robust activity against the isolates and could be used for empirical treatment ${ }^{15}$. However, according to our results the local population is fast becoming resistant to all of these agents and no single empirical treatment can be advised across the board. Hence, it becomes even more important that individual treatments be tailored according to the sensitivity patterns determined from urine culture. Otherwise we will be adding further resistance to antibiotics in the organisms responsible for bacteriuria.

\section{Conclusion}

The urine analysis of females with type-2 diabetes mellitus show a significant number of positive urine cultures. ESBL E. coli, the most frequently isolated organism, was resistant to commonly used antibiotics. The high resistance to antibiotics is of public health importance and highlights the need to administer antibiotics according to culture and sensitivity in order to avoid emergence of resistance strains.

\section{References}

1. Tandogdu Z, Wagenlehner FM. Global epidemiology of urinary tract infections. Curr Opin Infect Dis. 2016; 29(1): 73-9. Doi:10.1097/QCO.00000000 00000228

2. Olin SJ, Bartges JW. Urinary tract infections: treatment/comparative therapeutics. Vet Clin North Am Small Anim Pract. 2015; 45(4): 721-46. Doi:10.1016/j.cvsm.2015.02.005

3. Schneeberger C, Erwich HM, van den Heuvel ER, Mol BWJ, Ott A, Geerlings SE. Asymptomatic bacteriuria and urinary tract infection in pregnant women with and without diabetes: Cohort study. Eur J Obstet Gynecol Reprod Biol. 2018; 222: 176-81. Doi:10.1016/j.ejogrb.2017.12.013

4. Schneeberger C, Kazemier BM, Geerlings SE. Asymptomatic bacteriuria and urinary tract infections in special patient groups: women with diabetes mellitus and pregnant women. Curr Opin Infect Dis. 2014; 27(1): 108-114. Doi:10.1097/QCO.0000000000000028

5. Geerlings SE. Urinary tract infections in patients with diabetes mellitus: epidemiology, pathogenesis and treatment. Int J Antimicrob Agents. 2008; 31(Suppl 1): S54-S57. Doi:10.1016/j.ijantimicag.2007.07.042

6. Ye C, Kumar D, Carbonneau M, Keough A, Ma M, Tandon P. Asymptomatic bacteriuria is an independent predictor of urinary tract infections in an ambulatory cirrhotic population: a prospective evaluation. Liver Int. 2014; 34(6): e39-e44. Doi:10.1111/liv.12435

7. Yeshitela B, Gebre-Selassie S, Feleke Y. Asymptomatic bacteriuria and symptomatic urinary tract infections (UTI) in patients with diabetes mellitus in Tikur Anbessa Specialized University Hospital, Addis Ababa, Ethiopia. Ethiop Med J. 2012; 50(3): 239-249.

8. Nicolle LE. Asymptomatic bacteriuria. Curr Opin Infect Dis. 2014; 27(1): 90-6. Doi:10.1097/QCO.000000000000001

9. Schnarr J, Smaill F. Asymptomatic bacteriuria and symptomatic urinary tract infections in pregnancy. Eur J Clin Invest. 2008; 38 (Suppl 2): 50-7. Doi:10.1111/j.1365-2362.2008.02009.x

10. CLSI. CLSI Supplement M100S. 26th ed. Wayne, PA: Clinical and Laboratory Standards Institute; 2016. Performance Standards for Antimicrobial Susceptibility Testing

11. Givler DN, Givler A. Asymptomatic Bacteriuria. In: StatPearls. Treasure Island (FL): StatPearls Publishing; 2020.

12. Tahir N, Uddin QT. Frequency of urinary tract infection in diabetic females. KUST Med J 2009; 1(2): 55-58.

13. Bharti A, Chawla SPS, Kumar S, Kaur S, Soin D, Jindal N, Garg R. Asymptomatic bacteriuria among the patients of type 2 diabetes mellitus. J Family Med Prim Care. 2019; 8(2): 539-43. Doi:10.4103/jfmpc. jfmpc_403_18

14. Simkhada R. Urinary tract infection and antibiotic sensitivity pattern among diabetics. Nepal Med Coll J. $2013 ; 15: 1-4$

15. Boyko EJ, Fihn SD, Scholes D, Abraham L, Monsey B. Risk of urinary tract infection and asymptomatic bacteriuria among diabetic and nondiabetic postmenopausal women. Am J Epidemiol. 2005; 161:557-64 